\title{
Hypertrophy and hyperfunction of the diabetic kidney
}

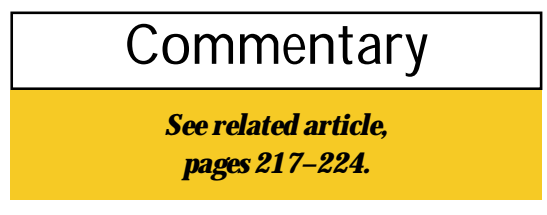

\author{
T.H. H ostetter \\ University of M innesota, M inneapolis, M innesota, USA, and N ational Institute of Diabetes, Digestive and Kidney Diseases, \\ $\mathrm{NIH}$, Bethesda, M aryland, USA
}

Address correspondence to: NIDDK, 6707 Democracy Boulevard, Room 625, Bethesda, M aryland 20892, USA. Phone: (301) 594-8864; Fax: (301) 480-3510; E-mail: hostettert@extra.niddk.nih.gov.

Diabetes is theleading cause of chronic renal failure. However, in the early phase of diabetes, beforecomplications have set in, the glomerular filtration rate (GFR) is el evated in a substantial portion of patients. Kidney size is al so increased. Thesetwo phenomena result from heightened single-nephron GFR and expanded nephron size, respectively. While the two observations are presumed to becausally linked, it remains to besettled which is causeand which is effect. The clinical importance of these early aberrations derives from two lines of evidence. The first and strongest shows that thehyperfiltration, or more accurately, the heighten ed glomerular capillary that drives thefiltration, damages the glomerulus (1). Second, some data also suggest that enlargement of thekidney, or glomerulus in particular, may contributeto nephropathy by abetting theaugmented filtration, by stresses or deficiencies imposed by excess size, or by both (2).

A number of primary abnormalities in vascular control leading to renal vasodilation have been proposed to account for the early hyperfiltration (1). H owever, a parallel view has held that primary augmentation of proximal tubular reabsorption stimulates increased filtration (3-5). This stimulation is envisioned as a consequence of the tubuloglomerular feedback (TGF) reflex. TGF responds to reductions in delivery of salt to the distal tubuleby vasodilation and enhancement of GFR until salt delivery returns to the set point. At the cellular level, the high concentrations of glucose in the diabetic filtrate promote that sodium reabsorption in the proximal tubule coupled to glucose.

Less clear isthelink of either hyperfiltration or hyperreabsorption to hypertrophy. Indeed, the somewhat broader question is unresolved as to whether GFR increases before or after renal mass in the residual kidney following con- tralateral nephrectomy. Both occur rapidly, and physiologic measurements in animals small enough for sensitive assessment of structural growth and repeated tests are fraught with complexities of confounding fluid volume losses and shifts.

This ignorance of temporal sequence underlies, in part, the puzzle as to whether increased reabsorptive work occasions structural growth through some locally generated metabolic growth factor, or whether growth proceeds and entrains increased filtration and reabsorption in its wake. Increased work can certainly instigateskeletal and cardiac growth, however it may be transduced. Also, the epithelial growth seen in nephron segments downstream to sites of diuretic action results from the extra reabsorptive burden they face (6). Another scenario might be entirely separatebut parallel processes directing increased function and structure, but this is unattractive. More attractive might be an iterative mechanism with increments in filtration/reabsorption reciprocating with and reinforcing increments in tissuegrowth. Whileperhaps neater, this compromisesidesteps the issue of prime mover - but who knows?

On the basis of pharmacological blockadeand detailed physiologic studies, Thomson and colleagues propose an admirably straightforward set of events to explain diabetic renal growth and hyperfunction (7). They suggest that initial kidney growth causes increased proximal reabsorption, and that in turn spurs filtration through theagency of TGF. Thesupport for this mechanism rests on partially blocking growth with an inhibitor of the polyamine synthetic enzyme ornithine decarboxylase. With the inhibitor, difluoromethylornithine, reabsorption and filtration are reduced in diabetic rats along with renal growth.
They may beright. H owever, as usual, some caveats apply. For example, this hypothesized pathway would predict that diabetic glomerular expansion would transpire at the same time, or perhaps even after, tubular growth rises if epithelial hypertrophy and hyperfunction were primary. But morphometric studies argue that the proximal tubule lags the glomerulus in this early growth, rather than tubular growth and reabsorption pulling glomerular growth (8). The authors do favor the notion that hyperglycemia boosts sodium reabsorption, but apparently in the absence of intact polyamine synthesis, the full expression of proximal reabsorption is blunted. So the primacy of growth is not so prime. Indeed, something more like the ratcheting interaction between work and growth is implied. The authors seem to prefer this effect of hyperglycemia as the prime mover, the necessary first step, albeit a step insufficient in itself to carry forward thefull-blown increase in structure and function (5). Of course, the inhibitor may be nonspecific for tubular growth and may be blocking vascular growth or even transduction of primary vasodilating signals, thereby masking an initial increase in GFR. Finally, elevations in extrarenal capillary pressures do occur in diabetes, for example in the nail fold (9). Since TGF is a regulator of vascular tone only within the kidney, these systemic changes suggest that primary vasomotor changes areal so at work in diabetes. Several therapeutic implications can be inferred from the results of Thomson et al. (7). The study convincingly demonstrates that the blocker substantially blunts diabetic hypertrophy and hyperfiltration. Thus, its use as a drug to ameliorate diabetic renal disease must be considered as an extension of its utility as a pathophysiologic probe. Also, blockers of proximal tubu- 
lar reabsorption should bebeneficial if theproposed pathogenetic chain is correct. The current standard means of mitigating diabetic nephropathy are glycemic control and angiotensin-converting enzyme inhibitors. This study raises the possibility that both may work in part by reducing proximal reabsorption, and in the case of converting enzyme inhibitors, blunting TGF, as angiotensin II, in addition to stimulating reabsorption, augments TGF as well $(10,11)$.

1. O'Bryan, G.T., and Hostetter, T.H. 1997. The renal hemodynamic basis for diabetic nephropathy. Semin. N ephrol. 17:93-100.

2. Hostetter, T.H. 1995. Progression of renal disease and renal hypertrophy. Annu. Rev. Physiol. 57:263-278.

3. Ditzel, J., and Brochner-Mortensen, J. 1983. Tubular reabsorption rates as related to elevated glomerular filtration in diabetic children. Diabetes. 32(Suppl.):28-33.

4. Bank, N., and Aynedjian, H.S. 1990. Progressive increases in luminal glucose stimulate proximal sodium absorption in normal and diabetic rats. J. Clin. Invest. 86:309-316.

5. Vallon, V., Richter, K., Blantz, R.C., Thomson, S.C., and Osswald, H. 1999. Glomerular hyperfiltration in experimental diabetes mellitus: potential role of tubular reabsorption. J. Am. Soc. Nephrol. 10:2569-2576.

6. Kaissling, B., and Stanton, B.A. 1988. Adaptation of distal tubule and collecting duct to increased sodium delivery. I. Ultrastructure.
Am. J. Physiol. 255:F1256-F1268.

7.Thomson, S.C., et al. 2001. Ornithine decarboxylase, kidney size, and the tubular hypothesis of glomerular hyperfiltration in experimental diabetes. J. Clin. Invest. 107:217-224.

8. Seyer-H ansen, K., H ansen, J., and Gundersen, H.J. 1980. Renal hypertrophy in experimental diabetes. A morphometric study. Diabetologia. 18:501-505.

9.Sandeman, D.D., Shore, A.C., and Tooke, J.E. 1992. Relation of capillary skin pressure in patients with insulin dependent diabetes mellitus to complications and metabolic control. N . Engl. J. Med. 327:760-764.

10. Schnermann, J. 1999. Micropuncture analysis of tubuloglomerular feedback regulation in transgenic mice. J. Am. Soc. N ephrol. 10:2614-2619.

11. Cogan, M.G. 1990. Angiotensin II: powerful controller of sodium transport in the early proximal tubule. Hypertension. 15:451-458. 